\title{
Combination therapy for dendritic keratitis with human leucocyte interferon and trifluorothymidine
}

\author{
E. W. J. DE KONING, ${ }^{1}$ O. P. VAN BIJSTERVELD,${ }^{1}$ AND K. CANTELL ${ }^{2}$ \\ From the 'Royal Netherlands Eye Hospital, F.C. Dondersstraat 65, Utrecht, Holland, and the \\ ${ }^{2}$ Central Public Health Laboratory, Mannerheimintie 166, SF-00280 Helsinki 28, Finland
}

SUMMARY Sixty-one patients were treated in a randomised double-masked clinical trial either with a combination of human leucocyte interferon 10 million $\mathrm{IU} / \mathrm{ml}$ and trifluorothymidine (TFT) in a $1 \%$ solution or with a combination of albumin placebo and trifluorothymidine. The healing time of dendritic keratitis was significantly lower with the combination of interferon and TFT than with the combination of placebo and TFT. For partial healing the reduction was $49 \%$ and for complete healing $42 \%$.

Herpes keratitis is still considered to be one of the most serious diseases of the outer eye. With the advent of virostatics ${ }^{1}$ in 1962 there has been progressive improvement in the treatment of dendritic keratitis. At present interferon treatment is at the centre of interest. It was discovered in 1957, but as it was very difficult to produce in large quantities experiments ${ }^{23}$ were limited.

Studies with interferon or interferon inducers alone $^{4-9}$ in controlling dendritic keratitis gave disappointing results. In combination with virostatics ${ }^{40}$ interferon was reported to be more effective than virostatics alone.

We have treated patients with dendritic keratitis and superficial epithelial lesions with interferon or placebo in combination with trifluorothymidine in a double-masked randomised trial.

\section{Material and methods}

Patients with dendritic keratitis or morphological variants were treated in a randomised arrangement with eye drops containing either human leucocyte interferon (HLI) 10 million $\mathrm{IU} / \mathrm{ml}$ and trifluorothymidine (TFT) in a $1 \%$ solution, or albumin placebo and trifluorothymidine in a $1 \%$ solution.

Patients with metaherpes, ${ }^{11}$ stromal keratitis, or who had previously received steroid treatment were excluded from the trial.

Correspondence to Dr E. W. J. de Koning. Stichting Koninklijk Nederlands Gasthuis voor Ooglijders, F.C. Dondersstraat 65 , Utrecht, Holland.
All patients received 5 drops of TFT daily. In addition they received every morning after careful eye examination one drop of $\mathrm{HLI}^{12}$ or placebo in a recumbent position. After 10 minutes a second drop was given, and the patients remained recumbent for another 10 minutes to ensure that the HLI or placebo kept in contact with the surface of the outer eye.

Before treatment we isolated herpes simplex virus from the cornea and conjunctiva by minimal wiping. Virus identification was done at the National Institute of Public Health in Bilthoven, The Netherlands. During transport and storage eye swabs were kept in GLY-medium, i.e., Hanks's balanced salt solution containing $0.5 \%$ gelatin, $0.5 \%$ lactalbumin hydrolysate, $0 \cdot 1 \%$ yeast extract, and antibiotics. The specimens were inoculated onto HEp-2 and on to $\mathrm{GaBi}$ cells (human diploid fibroblasts) in tubes. Cultures with characteristic cytopathic effect were identified as herpes simplex virus by serum neutralisation in $\mathrm{GaBi}$ cells. Typing was done in $\mathrm{GaBi}$ cells in microplate culture, with the use of rabbit antisera monospecific for type 1 and type 2 , respectively.

We used 2 criteria for healing: (1) partial healing, which we defined as closure of the epithelial wound only, i.e., no staining with fluorescein; and (2) complete healing, which we defined as closure of the epithelial wound without any epithelial oedema or cystic changes in the area of the previous dendrite. ${ }^{13}$ We gave the HLI or placebo until the third day of partial healing; the TFT was continued till complete healing. 


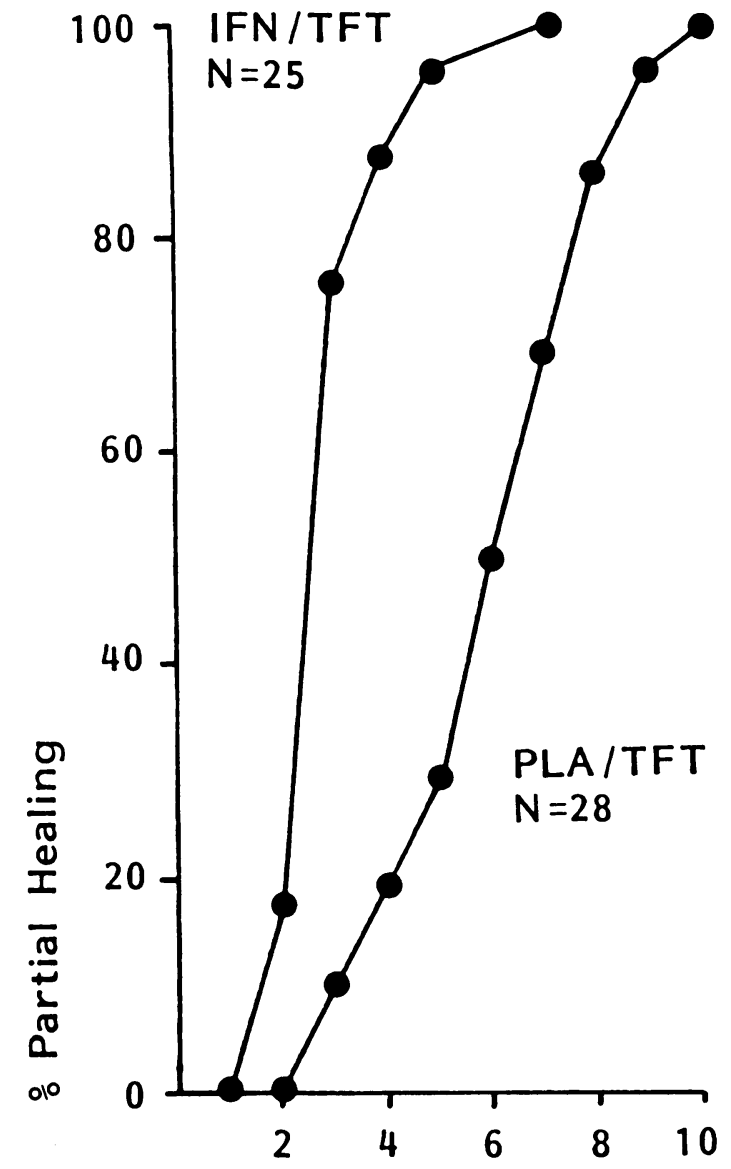

\section{Days to heal}

Fig. 1 Cumulative frequency graph for partial healing time of dendritic keratitis treated with interferon/TFT or placebo/TFT.

\section{Results}

Eight patients were excluded from the study, 2 because of omissions in complying with the examination protocol, one because he developed metaherpes; this patient received the placebo/TFT combination. Three patients were excluded because all herpes simplex virus isolations were negative. Two other patients developed severe stromal keratitis; both received the placebo/TFT combination.

Of the remaining 53 patients $(33$ males and 20 females) 25 were treated with HLI and TFT ( 15 males and 10 females) and 28 were treated with placebo and TFT (18 males and 10 females).

In Fig. 1 the number of days for partial healing of

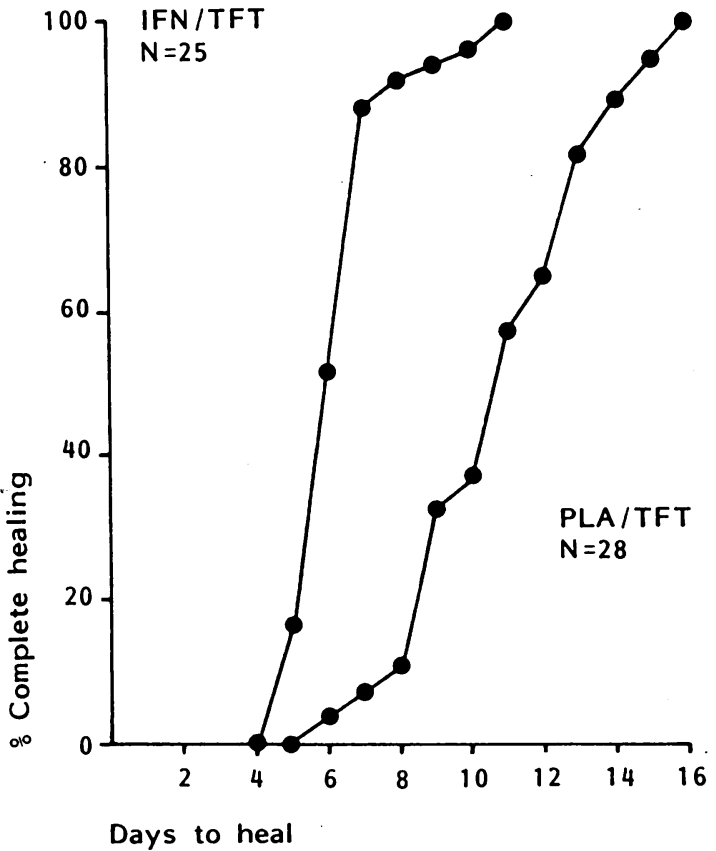

Fig. 2 Cumulative frequency graph for complete healing time of dendritic keratitis treated with interferon/TFT or placebo/TFT.

dendritic keratitis is given in a cumulative frequency graph. The average time for partial healing of the interferon/TFT treated group was $3 \cdot 3$ days and of the placebo/TFT treated group $6 \cdot 5$ days.

Table 1 is the table of analysis of variance for the data of partial healing. The treatment effect was statistically highly significant $(p<0 \cdot 01)$.

In Fig. 2 the number of days for complete healing of dendritic keratitis is given in a cumulative frequency graph. The average time for complete healing of the interferon/TFT treated group was 6.6 days and of the placebo/TFT treated group 11.3 days. The treatment effect of complete healing was also statistically highly significant $(p<0 \cdot 01)$.

Table 1 Analysis of variance of partial healing time

\begin{tabular}{llrrc}
\hline Nature of effect & Source & $\begin{array}{l}\text { Sum of } \\
\text { squares }\end{array}$ & DF & $\begin{array}{l}\text { Mean sum } \\
\text { of squares }\end{array}$ \\
\hline Main factors & Therapy (T)* & 136.94 & 1 & 136.94 \\
& Sex (S) & 2.32 & 1 & 2.32 \\
& Eye (E) & 0.93 & 1 & 0.93 \\
Interactions & T $\times$ S & $2 \cdot 37$ & 1 & 2.37 \\
& T $\times \mathrm{E}$ & 3.53 & 1 & 3.53 \\
Residual & S $\times \mathrm{E}$ & $1 \cdot 20$ & 1 & 1.20 \\
Total & & 111.68 & 46 & 2.43 \\
& & 258.97 & 52 & \\
\hline
\end{tabular}

$D F=$ degrees of freedom. $\quad * p<0.01$. 


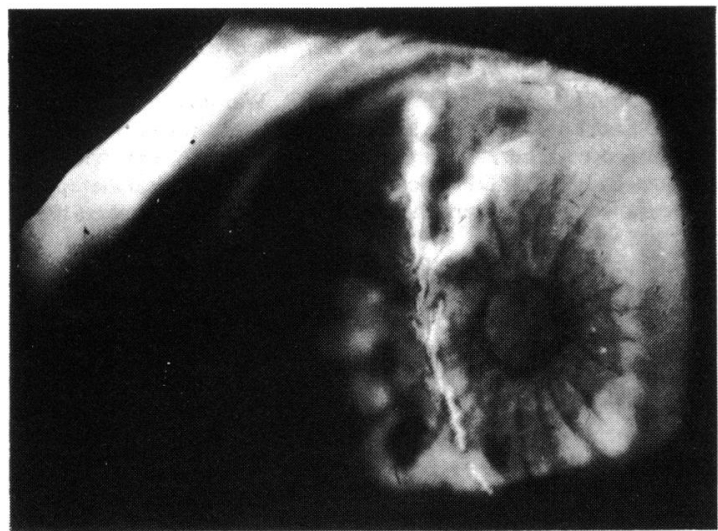

Fig. 3a

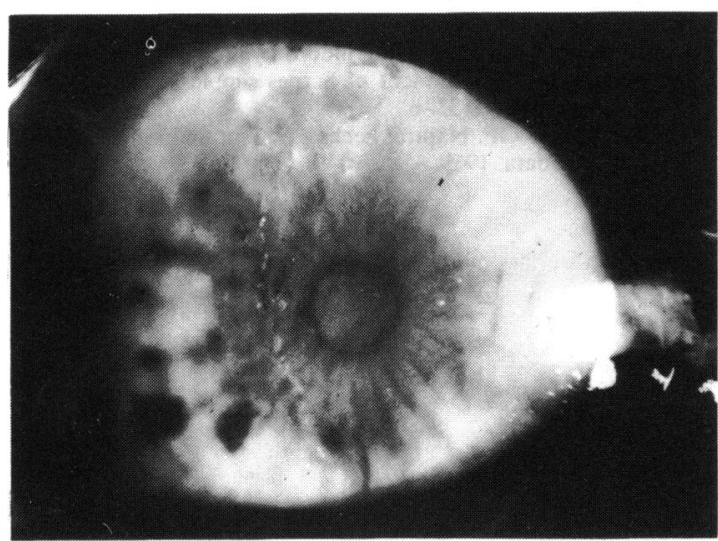

Fig. 3c

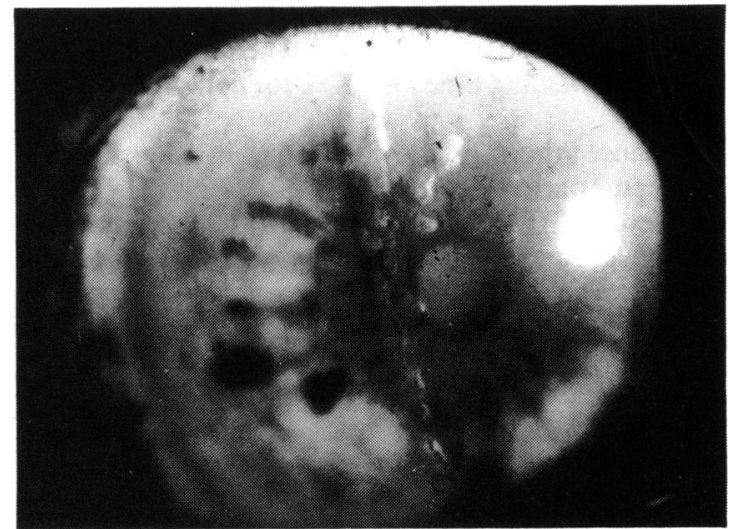

Fig. $3 b$

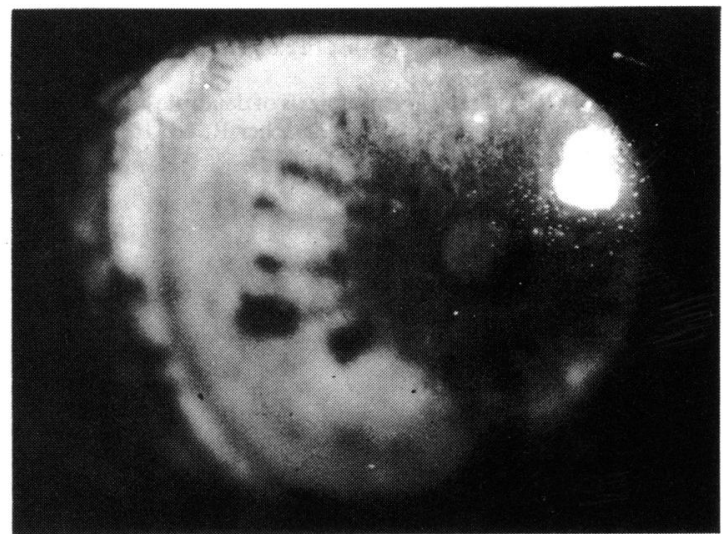

Fig. 3d

Fig. 3 These photographs show the healing process of dendritic keratitis after treatment with the interferon/TFT. (a) Before treatment. (b) One day after treatment. (c) Two days after treatment. (d) Three days after treatment.

The interval in days between partial and complete healing of dendritic keratitis for the interferon/TFT treated group was $3 \cdot 3$ days and for the placebo/TFT treated group 4.8 days. This difference was statistically significant $(\mathrm{p}<0 \cdot 01)$.

The healing process after treatment with interferon/ TFT is illustrated in Fig. 3, a-d.

\section{Discussion}

Only those corneal herpetic lesions were studied in this trial in which active virus replication was present in the epithelial cells. We therefore excluded metaherpes, which is considered to be a trophic herpetic disease, and also stromal forms in which immunological reactions rather than virus replication are the important factor.
Many authors ${ }^{4-9}$ have concluded that interferon or interferon inducers alone did not significantly reduce the healing time of dendritic keratitis as compared with the natural healing time.

Our results indicate that the combination of interferon and TFT gave a lower healing time for dendritic keratitis than TFT alone. In addition the 2 forms of treatment led to a quicker healing time than leaving the ulcers untreated. We have previously recorded a natural partial healing time of 13.8 days $(\mathrm{SD}=4 \cdot 1)$ and a natural complete healing time of 20 days $(\mathrm{SD}=3 \cdot 6) \cdot{ }^{14}$ In the present trial for TFT alone the comparable data are 6.5 days $(\mathrm{SD}=1.5)$ and 11.3 days $(\mathrm{SD}=2 \cdot 6)$ respectively. The percentage gain for TFT alone is $53 \%$ for partial healing and $44 \%$ for complete healing. If interferon is used in combination with TFT, these data are 3.3 days $(\mathrm{SD}=1 \cdot 1)$ and 6.6 
days $(\mathrm{SD}=1 \cdot 4)$ respectively. Here the percentage gain as compared with the natural healing time is $76 \%$ for partial healing time and $67 \%$ for complete healing time.

Because there is a difference in the interval between partial and complete healing of the interferon/TFT treated group and the placebo/TFT treated group, we may assume that the virus still exists in the period between partial and complete healing.

\section{References}

1 Kaufman HE, Martola EL, Dohlman C. Use of 5-iodo-2'deoxuridine (IDU) in treatment of herpes simplex keratitis. Arch Ophthalmol 1962; 68: 235-9.

2 Cantell K, Kirvonen S, Mogensen KE, Pyhala L. Human leucocyte interferon: production, purification, stability and animal experiments. In: Weymouth C. Proceedings of a tissue culture association workshop. Rockville: Tissue Culture Association, 1974: 35-8.

3 Cantell K. Prospects for clinical use of exogenous interferon. Med Biol 1977; 55: 69-73.

4 Sundmacher $R$. Therapy and profylaxis of dendritic keratitis with topical human interferon. In: Sundmacher R, ed. Herpetic Eye Diseases. Munich: Bergmann, 1981: 401-7.
5 Jones BR. Human interferon in topical therapy of herpetic keratitis. In: Sundmacher R, ed. Herpetic Eye Diseases. Munich: Bergmann, 1981: 395-400.

6 Kaufman HE. Meyer RF. Laibson PR, Waltmann SR, Nesburn AB. Shuster JJ. Human leucocyte interferon for prevention of recurrences of herpetic keratitis. J Infect Dis 1976; 133: A165-8.

7 Jones BR, Coster DJ, Falcon MG, Cantell K. Topical therapy of ulcerative herpetic keratitis with human interferon. Lancet 1976; ii: 128.

8 Nesburn AB, Ziniti PJ. Long-term topical poly I:C in experimental chronic ocular herpes simplex infection. Am J Ophthalmol 1971; 72: 821-6.

9 Centifanto YM, Goorha RM, Kaufman HE. Interferon induction in rabbit and human tears. Am J Ophthalmol 1970; 70: 1006-9.

10 Sundmacher R, Cantell K, Neumann-Haefelin D. Combination therapy of dendritic keratitis with trifluorothymidine and interferon. Lancet 1978; ii: 687.

11 van Bijsterveld OP. Volpini G. Metaherpes. Arq Bras Oftalmol 1979; 42: 4-6.

12 McGill JI, Collins P, Cantell K, Jones BR, Finter NB. Optimal schedules for use of interferon in the corneas of rabbits with herpes simplex keratitis. J Infect Dis 1976; 133: A13-7.

.13 van Bijsterveld $O P$, Post $H$. Trifluorothymidine versus adenine arabinoside in the treatment of herpes simplex keratitis. $\mathrm{Br} \mathrm{J}$ Ophthalmol 1980; 64: 33-6.

14 van Bijsterveld OP. Natural healing time in dendritic keratitis. Unpublished data, 1965. 